\title{
Stress testing of crisaborole by a novel stability indicating RP-HPLC method
}

\author{
Prafulla Kumar Sahu ${ }^{1}$ (D) Jagadeesh Panda ${ }^{1}$. V. V. Jogendra Kumar Yantapalli ${ }^{1}$ L. L. Manisha Piratla ${ }^{1}$
}

Received: 13 November 2019 / Accepted: 17 February 2020 / Published online: 10 March 2020

(c) Springer Nature Switzerland AG 2020

\begin{abstract}
An isocratic reverse phase high performance liquid chromatographic method has been developed for the determination of crisaborole (CRB), a novel non-steroidal topical phosphodiesterase-4-inhibitor. The analyte was separated on an Agilent eclipse XDB-C18 $(3.0 \times 150 \mathrm{~mm}, 3.5 \mu \mathrm{m})$ analytical column using water: acetonitrile $(30: 70 \mathrm{v} / \mathrm{v})$ as the mobile phase at a flow rate of $0.75 \mathrm{ml} / \mathrm{min}$ under ambient temperature and PDA detection at $254 \mathrm{~nm}$. Added to this, several validation parameters were exercised on the developed HPLC method as per ICH guidelines. Method variables, viz., mobile phase flow rate $(0.75 \pm 0.1 \mathrm{ml} / \mathrm{min})$ and percentage of organic modifier in mobile phase $(70 \pm 5 \%)$ were studied by a central composite design for testing the robustness of the proposed method. The method was found to be linear in the concentration range of $2-100 \mu \mathrm{g} / \mathrm{ml}\left(r^{2}=0.999\right)$ and precise ( $\left.\mathrm{RSD}^{`} 2 \%\right)$ satisfying regulatory criteria. The method was found to be robust and ambiguity of worst result for certain responses still are acceptable and likely to occur due to the effect of extreme experimental conditions. Stress testing of CRB was carried out under acid, base, thermal, photolysis, peroxide and neutral conditions. Separation of the forced degradation products from the main analyte was accomplished using a gradient elution of the mobile phase consisting acetonitrile from 0 to $100 \%$ in water at a flow rate of $1.2 \mathrm{ml} / \mathrm{min}$.
\end{abstract}

Keywords RP-HPLC · Crisaborole · Stability indicating method $\cdot$ Stress testing $\cdot$ Validation $\cdot$ Robustness testing

\section{Introduction}

CRB is a newly approved (USFDA; 14th December, 2016) non-steroidal topical phosphodiesterase-4-inhibitor for the treatment of mild to moderate atopic dermatitis (MMAD) in children and adults [1,2]. Chemically, it is 4-[(1-hydroxy-1,3-dihydro-2,1-benzoxaborol-5-yl)oxy] benzonitrile (Fig. 1). The drug was assessed for its safety and efficacy in patients $\geq 2$ years old with Phase 3 studies $[3,4]$. A long-term safety assessment of CRB ointment $2 \%$ was studied for 48 -weeks in patients $(N=517) \geq 2$ years of age with MMAD [5]. The carcinogenic potential of CRB was tested for application of the ointment to mice and female rats over a period of 2-years. It was proven that the drug is well tolerated and non-tumorigenic [6]. Two case studies were presented to demonstrate successful treatment of psoriasis in patients with CRB therapy [7]. The impact of CRB therapy for the treatment of MMAD was assessed in two identically designed phase 3 studies based on improvement in quality of life index for patients and their parents/caregivers/families [8].

Up to now a single HPLC-UV method is available for extraction and assay of CRB in stripped skin layers from pig ears after an in-vitro permeation experiment [9]. However, no stability-indicating method is reported for the estimation of CRB in ICH stress testing conditions. Hence, the present work aims at development and validation of a simple, robust and efficient RP-HPLC method for the estimation of $\mathrm{CRB}$ and its stress impurities via stability studies.

Prafulla Kumar Sahu, kunasahu1@rediffmail.com | 'Department of Pharmaceutical Analysis, Raghu College of Pharmacy, Dakamarri, Bheemunipatnam (M), Visakhapatnam, Andhra Pradesh 531 162, India. 


\section{Materials and methods}

\subsection{Chemicals and reagents}

Pharmaceutical grade CRB of $99.98 \%$ purity (according to the certificate of analysis of manufacturer) was provided as a gift sample from a local pharmaceutical industry, Hyderabad, Telangana, India. Ultra pure water was obtained from Millipore, Milli-Q plus water purified system (Bedford, MA, USA) and used for making the solutions. HPLC grade acetonitrile were purchased from the local market (Merck, India). Other chemicals such as sodium hydroxide, hydrochloric acid and hydrogen peroxide were of analytical-reagent grade from Finar Chemicals (Mumbai, India).

\subsection{Apparatus and equipments used}

Analysis of the sample was performed on a HPLC system composed of two LC-20AD pumps, an SPD-M20A photo diode array detector (Shimadzu, Kyoto, Japan). An Agilent eclipse XDB-C18 $(3.0 \times 150 \mathrm{~mm}, 3.5 \mu \mathrm{m})$ analytical column was used for separation. The chromatographic data integration was done by LC Solution software (Shimadzu, Kyoto, Japan). A precision water bath furnished with MV controller (Thermostatic Classic Scientific India Ltd, Mumbai, India) was used for hydrolytic study. A humidity chamber (Labline Sun Scientific Ltd. New Delhi, India) for stability studies and a photo stability chamber (95 Th-400G, Thermolab, Mumbai, India) for photolytic study were used. Thermal stability study was carried out in a hot air oven (Kumar Scientific Works, Pune, India). A pH meter (Elico) was used for $\mathrm{pH}$ adjustment of solutions.

\subsection{Preparation of analytical solutions}

Stock solution ( $1 \mathrm{mg} / \mathrm{ml}$ ) was prepared by dissolving the appropriate amount of standard CRB in acetonitrile. Working solutions $(100 \mu \mathrm{g} / \mathrm{ml})$ were prepared by adequately mixing the stock solutions with the diluent [water and

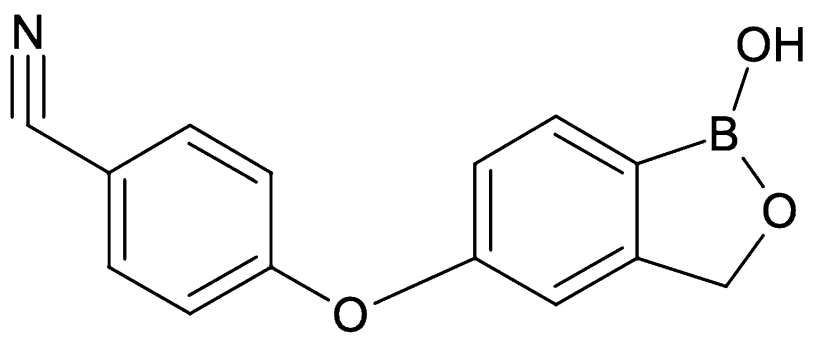

Fig. 1 Chemical structure of crisaborole (4-[(1-hydroxy-1,3-dihydro2,1-benzoxaborol-5-yl)oxy]benzonitrile) acetonitrile (50:50)]. The obtained working standard solution was adequately diluted to get suitable concentrations for the execution of method validation exercises.

\subsection{Specificity and stress degradation studies}

Stock solutions of $1 \mathrm{ml}$ each was used to perform all stress degradation studies. Acid and alkaline hydrolysis were executed by heating the drug solutions in $1 \mathrm{ml}$ each of $1 \mathrm{M} \mathrm{HCl}$ and $1 \mathrm{M} \mathrm{NaOH}$ at $60^{\circ} \mathrm{C}$ for $30 \mathrm{~min}$. Stress testing under neutral condition was studied by heating the drug dissolved in water at $60^{\circ} \mathrm{C}$ for $6 \mathrm{~h}$. For study in oxidative condition, the drug solution was kept at $60^{\circ} \mathrm{C}$ in $1 \mathrm{ml}$ of $20 \%$ hydrogen peroxide for $30 \mathrm{~min}$. For photolytic study, the drug solution was exposed to UV Light $\left(200-\mathrm{Wh} / \mathrm{m}^{2}\right)$ for 7 days. Additionally, the solid drug (API powder) of $100 \mathrm{mg}$ was exposed to dry heat at $105^{\circ} \mathrm{C}$ for $72 \mathrm{~h}$ in a hot air oven to perform the thermal degradation study. After the stipulated time, the samples were withdrawn and subjected to HPLC analysis soon after suitable dilution $(100 \mu \mathrm{g} / \mathrm{ml})$ and neutralisation as appropriate.

\subsection{Chromatographic separation}

An Agilent eclipse XDB-C18 $(3.0 \times 150 \mathrm{~mm}, 3.5 \mu \mathrm{m})$ analytical column in ambient temperature was used with a mobile phase comprised of water: acetonitrile $(30: 70 \mathrm{v} / \mathrm{v})$ pumped at a flow rate of $0.75 \mathrm{ml} / \mathrm{min}$ for the rapid assay of CRB. A gradient elution of the mobile phase consisting acetonitrile from 0 to $100 \%$ in water at a flow rate of $1.2 \mathrm{ml} / \mathrm{min}$ was accomplished for separation of the forced degradation products from the main analyte. For all the studies, the sample injection volume was set to $10 \mu \mathrm{L}$ and photo diode array detection of the column effluents was done at $254 \mathrm{~nm}$.

\subsection{Method validation}

The analytical method was validated for the following parameters as per ICH guidelines Q2 (R1).

\subsubsection{Linearity and range}

The linearity of the method was determined in concentration range of $2-100 \mu \mathrm{g} / \mathrm{ml}$. Each solution was injected in triplicate. The peak area versus concentration data of the drug was treated by least squares linear regression analysis. 


\subsubsection{Precision}

Intra-day precision of the method was determined using three quality control samples $(20,50$ and $80 \mu \mathrm{g} / \mathrm{ml}$ ) each three injections on the same day and percentage relative standard deviation (\%RSD) were calculated. Furthermore, these experiments were repeated on three consecutive days to assess inter-day precision.

\subsubsection{Specificity}

The specificity of the method was established through study of resolution of the main analyte peak from the nearest degradant peaks.

\subsubsection{Detection and quantification limits}

Sensitivity of the method was studied by establishing the limit of detection $[\mathrm{LOD}=3.3(\sigma / \mathrm{S})]$ and limit of quantitation $[\mathrm{LOQ}=10(\sigma / \mathrm{S})]$. Where, $\sigma$ is the standard deviation of the response and $S$ is the slope from the calibration curve.

\subsubsection{Central composite design aided robustness testing}

It is an important regulatory criterion to establish the robustness of the optimized method. It has been stated that "Robustness of an analytical method is the property that indicates insensitivity against changes of known operational parameters on the results of the method and hence its suitability for its defined purpose" [10].

Table 1 Operational parameters selected along with their levels for robustness testing of the method by CCD

\begin{tabular}{llll}
\hline Operational parameters & Low & Optimal & High \\
\hline Flow rate $(\mathrm{ml} / \mathrm{min})$ & 0.65 & 0.75 & 0.85 \\
\%B in mobile phase & 65 & 70 & 75 \\
\hline
\end{tabular}

Contrary to traditional trial and error strategy, uses of design of experiments (DoE) were evidenced to furnish more valid results to establish how robust the method is $[11,12]$. In the present study, we have considered to determine the robust domain (tolerable variations) via response surfaces using a CCD. The study was limited to investigating the influence of the basic HPLC parameters only. Two key parameters viz. flow of mobile phase $(\mathrm{ml} /$ $\mathrm{min}), \% B$ in the mobile phase were studied [Table 1] at 3 levels for 13 experimental trials. Chromatographic factors such as retention time (Rt), peak area and tailing factor $(T)$ were adapted as the responses to be investigated. The responses obtained for all the 13 experimental runs were then ensured for reproducibility and to be within the acceptable criteria.

\section{Results and discussion}

\subsection{Method development and optimisation}

Initially, an isocratic RPHPLC method for rapid assay of CRB was developed. The optimisation of the method was accomplished on the basis of best peak parameters and shape with the simplest and inexpensive mobile phase. The chromatogram at optimal condition for fast analysis is portrayed in Fig. 2. Further, the method is modified with the help of gradient elution of mobile phase to separate CRB from its major degradants formed under various stress conditions. Figure $3 a$ demonstrates that the peak of unstressed CRB is free from any interference and the method suitably possess the power of a stabilityindicating method.
Fig. 2 Chromatogram of standard crisaborole under optimal method condition during rapid assay procedure

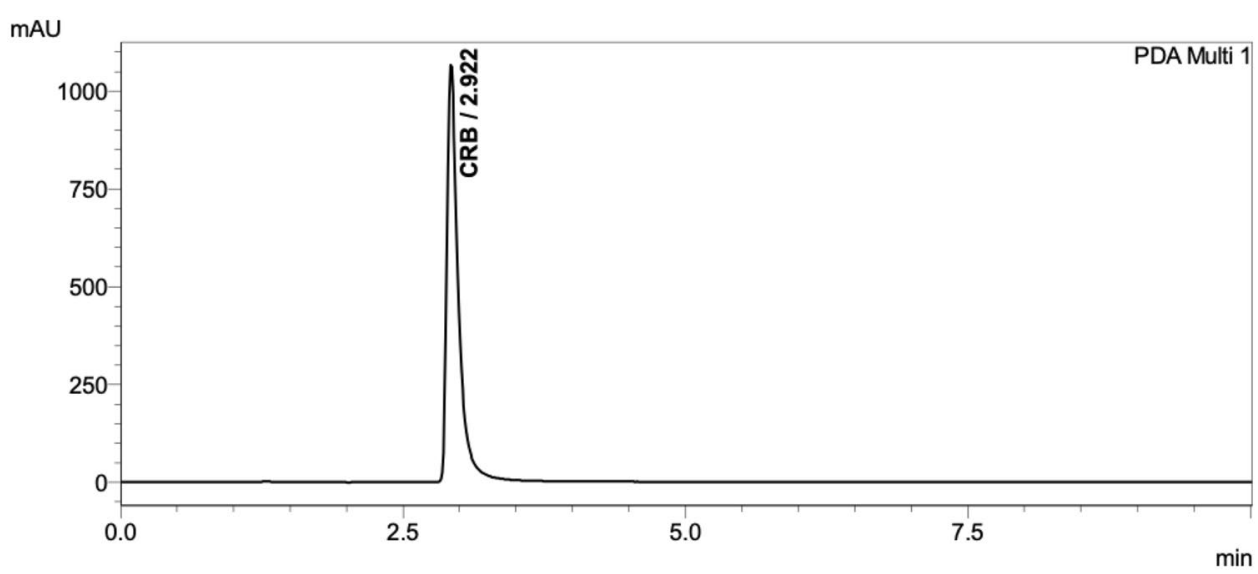




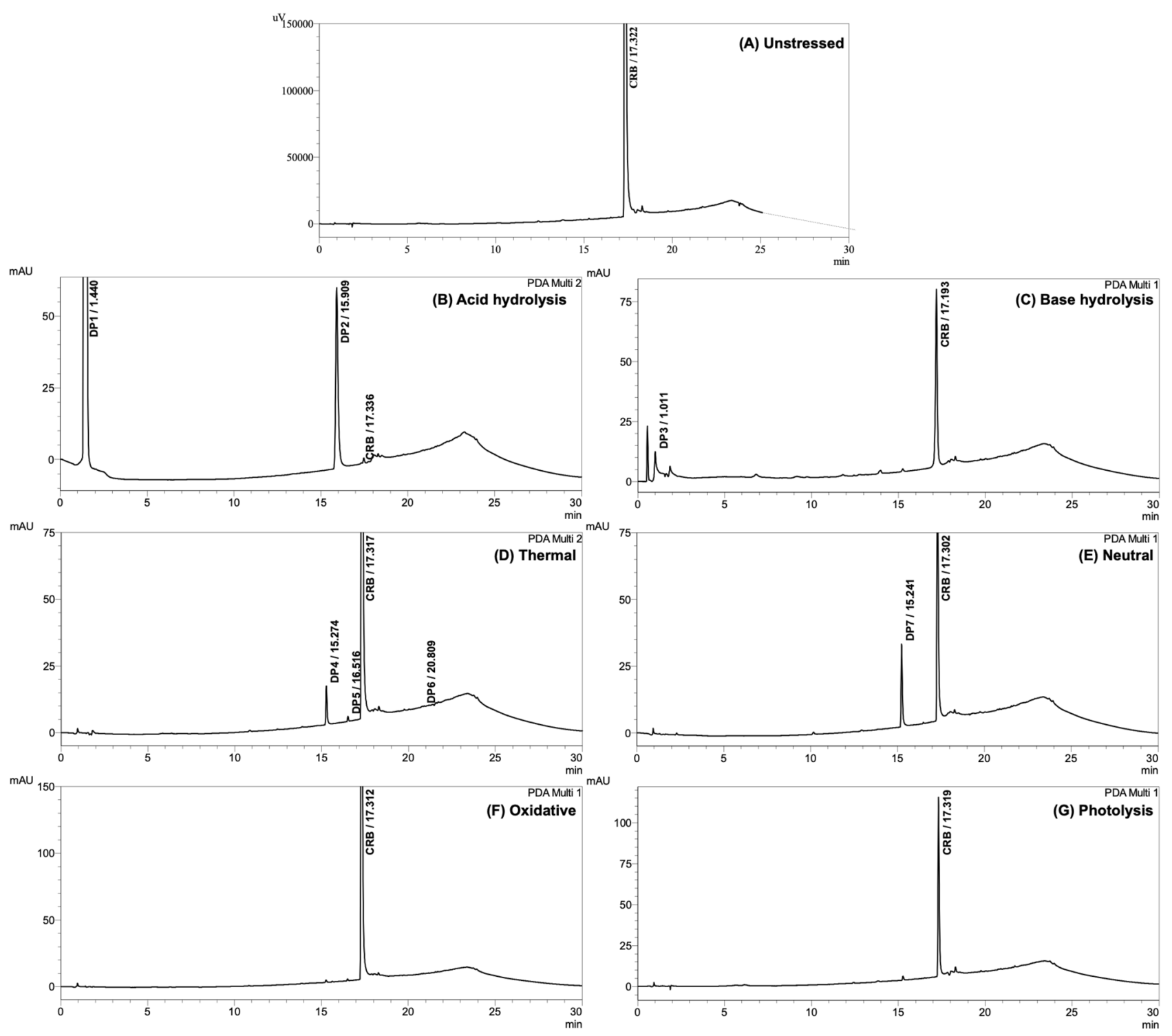

Fig. 3 Chromatograms of the stressed drug solutions obtained during forced degradation study

\subsection{Method validation}

\subsubsection{Robustness testing}

The robustness study was designed for assessing the ability of the RP-HPLC method to remain unbiased by small variations in the two key operational parameters (mobile phase flow, percent organic modifier). A CCD was adapted to module the influence of the basic parameters on the method performance mathematically. Retention time $(R t)$, tailing factor $(T)$ and peak area of CRB were considered as method performance index. CCD experimental designs are based on three-level factorial designs and classified as rotatable or nearly rotatable second-order response surface designs. Unlike full factorial or other optimisation designs, CCD is simple, convenient, less expensive and more efficient. The factor settings with the resulted HPLC responses for 13 experimental runs are shown in the following design matrix (Table 2). The main objective behind this approach is for easy verification of quantitative responses that are expected to be insensitive to changes in method parameters. That means the quantitative response situated at any of the points of the experimental domain must agree in $95 \%$ of the experiments executed at the defined condition. However, testing at conditions stricter than the usual does not accept the hypothesis and certain responses tend to have their worst results. Analysing the variance (Table 3 ) for $R t$, peak area and $T$ revealed that regression models were significant violating respective 
Table 2 Central composite design and responses obtained for testing robustness of the RP-HPLC method

\begin{tabular}{lllllll}
\hline Run & Factors & & \multicolumn{3}{l}{ Responses } \\
\cline { 2 - 3 } \cline { 5 - 6 } \cline { 5 - 6 } & Flow rate & $\% \mathrm{~B}$ (Acetonitrile) & & $R t$ & $T$ & Peak area \\
\hline 1 & 0.75 & 70 & 2.885 & 1.782 & $3.19728 \mathrm{E}+06$ \\
2 & 0.85 & 75 & & 2.384 & 1.794 & $2.77487 \mathrm{E}+06$ \\
3 & 0.75 & 70 & 2.9 & 1.796 & $3.17631 \mathrm{E}+06$ \\
4 & 0.75 & 70 & 2.9 & 1.806 & $3.12833 \mathrm{E}+06$ \\
5 & 0.85 & 65 & 2.789 & 1.851 & $2.75438 \mathrm{E}+06$ \\
6 & 0.75 & 62.9289 & 3.291 & 1.786 & $2.33285 \mathrm{E}+06$ \\
7 & 0.608579 & 70 & 3.55 & 1.68 & $2.87171 \mathrm{E}+06$ \\
8 & 0.75 & 70 & 2.895 & 1.774 & $2.32688 \mathrm{E}+06$ \\
9 & 0.75 & 70 & 2.882 & 1.789 & $3.11816 \mathrm{E}+06$ \\
10 & 0.65 & 65 & 3.623 & 1.742 & $3.57848 \mathrm{E}+06$ \\
11 & 0.75 & 77.0711 & 2.639 & 1.663 & $3.14358 \mathrm{E}+06$ \\
12 & 0.65 & 75 & 3.109 & 1.642 & $3.6187 \mathrm{E}+06$ \\
13 & 0.891421 & 70 & 2.427 & 1.814 & $1.98725 \mathrm{E}+06$ \\
\hline
\end{tabular}

$95 \%$ confidence intervals for each of the method variables ( $p$ value ${ }^{\prime} 0.05$ ). This indicates that the responses are situated far above $95 \%$ probability limit considering the modified method parameters (flow rate of $0.75 \pm 0.1 \mathrm{ml}$ ) min and $\% B$ in mobile phase of $70 \pm 5 \%$ ), which is much stricter than the possible acceptable experimental conditions and will only be met rarely in a laboratory. An easier and less strict alternative situation could lead to acceptable quantitative results.

$\mathrm{ICH}$ recommends that the system suitability limits are to be studied too strictly during method optimisation, which enables to explore the most extreme variations in the method that are likely to occur. However, for practical reasons the most extreme situation is not considered desirable to define system suitability limits, even if quantitation still is possible [13]. Therefore, it is always good to adhere closer to the conditions at which the method was validated. The most extreme $R t$ (3.55) and $T$ (1.85) from the design results are still closer to the values at nominal condition of the method [ $R t$ (2.89) and T (1.8). Hence, it is demonstrated that the deliberate variations in operational parameters did not observe any drastic alteration in the separation performance and the developed method was considered to be robust.

\subsubsection{Linearity and sensitivity}

Calibration curve was obtained by plotting respective peak areas against drug concentrations. The method demonstrated good linearity $[y=158,162 \times-62,684$, and determination coefficient $\left(r^{2}\right)=0.999$ ] in the concentration range of $2-100 \mu \mathrm{g} / \mathrm{ml}$. Sensitivity of the method was studied by establishing the limit of detection $(L O D)=3.3$ $(\sigma / \mathrm{S})$ and limit of quantitation $(\mathrm{LOQ})=10(\sigma / \mathrm{S})$; where, $\sigma$ is the standard deviation of the response and $S$ is the slope of the calibration curve. The measured LOD was 0.185 and LOQ $0.56 \mu \mathrm{g} / \mathrm{ml}$.

\subsubsection{Precision studies}

All the experiments for precision study were conducted in triplicates and obtained data were summarised in Table 4. Studies for intra and inter-day precision of the developed RP-HPLC method were performed for QC samples at three different concentrations 20,50 and $80 \mu \mathrm{g} / \mathrm{ml}$. The method was considered to be precise, where the estimated $\%$ RSD was $<1.727 \%$.

Table 4 Inter and intra-day precision data when performed in triplicate

\begin{tabular}{lll}
\hline $\begin{array}{l}\text { Theoretical concen- } \\
\text { tration }(\mu \mathrm{g} / \mathrm{ml})\end{array}$ & $\begin{array}{l}\text { Inter-day } \\
\text { Actual concentration }(\mu \mathrm{g} / \mathrm{ml}) \text { found } \\
(\text { mean } \pm \text { SD; } \% \mathrm{CV})\end{array}$ \\
\hline 20 & $20.026 \pm 0.058 ; 0.29$ & $19.905 \pm 0.082 ; 0.413$ \\
50 & $50.185 \pm 0.321 ; 0.639$ & $50.495 \pm 0.872 ; 1.727$ \\
80 & $78.1 \pm 0.17 ; 0.217$ & $77.933 \pm 0.336 ; 0.431$ \\
\hline
\end{tabular}

Table 3 ANOVA results for the three critical responses

\begin{tabular}{|c|c|c|c|c|c|c|}
\hline \multirow[t]{2}{*}{ Variables } & \multicolumn{2}{|l|}{$R t$} & \multicolumn{2}{|l|}{$T$} & \multicolumn{2}{|c|}{ Peak area } \\
\hline & F-value & $p$ value & F-value & $p$ value & F-value & $p$ value \\
\hline Model & 6007.15 & $<0.0001$ & 33.84 & $<0.0001$ & 6.70 & 0.0252 \\
\hline A-FLOW & $22,042.33$ & $<0.0001$ & 75.93 & $<0.0001$ & 6.70 & 0.0252 \\
\hline B-B & 7543.25 & $<0.0001$ & 40.98 & 0.0002 & & \\
\hline$A B$ & 52.88 & 0.0002 & & & & \\
\hline$A^{2}$ & 284.46 & $<0.0001$ & 5.21 & 0.0518 & & \\
\hline$B^{2}$ & 162.08 & $<0.0001$ & 15.26 & 0.0045 & & \\
\hline Lack of fit & 0.5048 & 0.6995 & 3.37 & 0.1330 & 1.24 & 0.4428 \\
\hline
\end{tabular}




\subsection{Degradation behaviour of crisaborole}

Stress testing of CRB under several conditions with the aid of RP-HPLC suggested the following degradation behaviour.

\subsubsection{Acid hydrolysis}

Significant fall in peak area of CRB was observed when it was subjected to acid hydrolysis. The drug is highly labile forming two major degradation products at $R t$ of 1.440 (DP1) and $15.909 \mathrm{~min}$ (DP2) respectively (Fig. 3b). Maximum degradation of the drug (99.99\%) was observed in acidic condition when compared to other stress conditions.

\subsubsection{Base hydrolysis}

Upon heating the drug solution with $1 \mathrm{M} \mathrm{NaOH}$ at $60^{\circ} \mathrm{C}$ for $30 \mathrm{~min}$, a degradation peak was formed at $R t$ of $1.011 \mathrm{~min}$ (DP3). A steep fall in peak area (24.13\%) demonstrated that the drug is vulnerable to degrade when exposed to alkaline condition (Fig. 3c).

\subsubsection{Thermal}

Degradation of CRB was observed when the drug was subjected to thermal condition. Figure $3 \mathrm{~d}$ endorsed that the degradation is associated with rise in three degradants peaks at Rt of 15.274 (DP4), 16.516 (DP5) and $20.809 \mathrm{~min}$ (DP6) respectively. Upon completion of the stress duration, a fall (2.8\%) in the drug peak area was observed.

\subsubsection{Neutral hydrolysis}

When the drug dissolved in water was heated at $60{ }^{\circ} \mathrm{C}$ for $6 \mathrm{~h}$, a degradant peak at $R t$ of $15.241 \mathrm{~min}$ (DP7) was observed. Figure $3 e$ demonstrated that CRB is highly susceptible to neutral hydrolysis with significant degradation of $18.85 \%$. Substantial degradation of the drug demonstrates its vulnerability to hydrolyse in acid, alkali and water.

\subsubsection{Oxidative and photolysis}

CRB was found to be stable when subjected to either oxidative or photolytic stress conditions and no decomposition was observed. The obtained chromatograms were presented in Fig. $3 f$, g respectively.

From the forced degradation study, it was revealed that CRB is prone to degrade under acid, base, neutral (hydrolytic) and thermal stress conditions and is stable to oxidation and photolysis (UV light). The magnitude of drug degradation measured was in the range of acid $>$ base $>$ neutral $>$ thermal. The homogeneity and purity of CRB peak in all analysed stress samples was confirmed by peak purity test (PDA detector). The obtained chromatograms (Fig. 3) endorse that all the formed degradants were well separated from CRB and each other confirming the specificity and stability-indicating power of the RP-HPLC method.

\section{Conclusion}

A novel stability indicating RPHPLC method was developed for the determination of CRB in presence of its forced degradation products. The separation was achieved on an Agilent eclipse XDB-C18 $(3.0 \times 150 \mathrm{~mm}, 3.5 \mu \mathrm{m})$ analytical column using water: acetonitrile as the mobile phase under ambient temperature and PDA detection at $254 \mathrm{~nm}$. The method was validated as per $\mathrm{ICH}$ guidelines and found to be sensitive, precise, robust and specific. The stress behaviour of CRB revealed that it is highly susceptible to degrade under acid, base, neutral (hydrolytic) and thermal stress conditions and is stable to oxidation and photolysis (UV light). The magnitude of drug degradation measured was in the range of acid $>$ base $>$ neutral $>$ thermal. The homogeneity and purity of CRB peak in all analysed stress samples was confirmed by peak purity test (PDA detector). The study endorsed that all the formed degradants were well separated from CRB and each other confirming the specificity and stability-indicating power of the RP-HPLC method.

\section{Compliance with ethical standards}

Conflict of interest All the authors declare that they have no conflict of interest.

Ethical approval This article does not contain any studies with human participants or animals performed by any of the authors.

\section{References}

1. Hussar DA, Lee Y (2017) Crisaborole, dupilumab, and sarilumab. J Am Pharm Assoc 57:640-643

2. Kailas A (2017) Crisaborole: a new and effective nonsteroidal topical drug for atopic dermatitis. Dermatol Ther 30:e12533

3. Paller AS, Tom WL, Call RS, Eichenfield L, Forsha D, Rees WC, Zane LT, Hebert AA (2016) Phase 3 studies in atopic dermatitis with the novel, nonsteroidal topical phosphodiesterase 4 inhibitor, crisaborole. J Invest Dermatol. https://doi.org/10.1016/j. jid.2016.02.316

4. Paller AS, Tom WL, Lebwohl MG, Blumenthal RL, Boguniewicz M, Call RS, Eichenfield LF, Forsha DW, Rees WC, Simpson EL, Spellman MC, Stein Gold LF, Zaenglein AL, Hughes MH, Zane 
LT, Hebert AA (2016) Efficacy and safety of crisaborole ointment, a novel, nonsteroidal phosphodiesterase 4 (PDE4) inhibitor for the topical treatment of atopic dermatitis (AD) in children and adults. J Am Acad Dermatol 75:494-503

5. Eichenfield LF, Call RS, Forsha DW, Fowler J, Hebert AA (2017) Long-term safety of crisaborole ointment $2 \%$ in children and adults with mild to moderate atopic dermatitis. J Am Acad Dermatol 77:641-649

6. Ciaravino V, Coronado D, Lanphear C, Chanda S (2017) 2-Year animal carcinogenicity results for crisaborole, a novel phosphodiesterase 4 inhibitor for atopic dermatitis. J Dermatol Sci $87: 116-122$

7. Lee EB, Lebwohl MG, Wu JJ (2019) Treatment of psoriasis with crisaborole. J Dermatol Treat 30:156-157

8. Simpson EL, Paller AS, Boguniewicz M, Eichenfield LF, Feldman SR, Silverberg Jl, Chamlin SL, Zane LT (2018) Crisaborole ointment improves quality of life of patients with mild to moderate atopic dermatitis and their families. Dermatol Ther 8:605-619

9. Demurtas A, Pescina S, Nicoli S, Santi P, Padula C (2019) Development and validation of a simple method for the extraction and quantification of crisaborole in skin layers. Biomed Chromatogr 33:e4664. https://doi.org/10.1002/bmc.4664

10. Sahu PK, Rao RN, Cecchi T, Swain S, Patro CS, Panda J (2018) An overview of experimental designs in HPLC method development and validation. J Pharm Biomed Anal 147:590-611

11. Sahu PK (2017) Determination of system suitability limits with a robustness test. J Anal Bioanal Tech 8:363-370

12. Sahu PK, Panda J, Jogendra Kumar YVV, Karunya SR (2020) A robust RP-HPLC method for determination of turmeric adulteration. J Liq Chromatogr Relat Technol. https://doi. org/10.1080/10826076.2020.1722162

13. Vander Heyden Y, Jimidar M, Hund E, Niemeijer N, Peeters R, Verbeke JS, Massart DL, Hoogmartens J (1999) Determination of system suitability limits with a robustness test. J Chromatogr A 845:145-154

Publisher's Note Springer Nature remains neutral with regard to jurisdictional claims in published maps and institutional affiliations. 